\title{
Grassroots Campaign in Technology-Enabled Elections: Madurai and Thiruvananthapuram in 2019 Indian Elections
}

\author{
Drupa Dinnie Charles \\ Microsoft Research India \\ v-drdinn@microsoft.com
}

\author{
Azhagu Meena S P \\ Microsoft Research India \\ v-meazha@microsoft.com
}

\author{
Joyojeet Pal \\ Microsoft Research India \\ joyojeet.pal@microsoft.com
}

\begin{abstract}
As a critical site of democratic action, the grassroots electoral campaigning is undergoing a transformation with the influence of digital tools in mobilizing the electorate. Through an ethnographic study conducted in Madurai and Thiruvananthapuram during the months prior to the 2019 Indian Parliamentary Elections, the study attempts to map the technology adoption among political workers, in relation to their party/leaders, voters, and other stakeholders in the electoral landscape. Using the typology presented in the new repertoire of social movement action, we categorize the internet-based and internet-supported campaigning tools, according to the threshold of risk and effort involved in undertaking the activities. Illustrating with perspectives from the grassroots political agents, the paper aspires to extend the literature related to digital political mobilization and contribute to the study of democratic systems.
\end{abstract}

\section{Introduction}

The election festivities were at a fever pitch in Madurai and Thiruvananthapuram - party rented jeeps blaring political slogans, the city walls decorated with party colours and symbols, banners and flags hung pole to pole and party workers fervently canvassing at every corner. As ubiquitous was another, more silent election noise of constantly lighting up smart phone screens in almost every hand. The 2019 Indian election was fought on the ground, as much as it was fought on the virtual space, one interweaving with the other.

In this paper, we present an ethnographic report of campaign politics from these two constituencies in the 2019 Indian general elections. Through the lens of a typology for digital action in social movements presented by Jeroen Van Laer \& Peter Van Aelst[1], we attempt to understand the kinds of activities that grassroots-level campaigners undertake in a large electoral event and how they have been impacted by technology adoption in this space. While there is much recent work on politicians and their use of technology, particularly social media, little substantial work exists on how the routine functions of an electoral campaign have changed, in particular, how the work of grassroots political workers who do the door-to-door campaigning and voter mobilization has changed. In this research, we seek to answer the following research questions:

1. How has digital technology changed the functional aspects of grassroots political workers' outreach?

2. How do grassroots political workers perform their new functions which have come into practice because of their access to the digital technology?

For ease of understanding throughout this work, we use internet or digital technology to refer to a range of services provided through the internet and mobile communications networks including social networking sites, app based platforms, websites, search engines, meme/gif/poster/image generating software and the affordances that these avenues provide.

\section{Related Work}

Political Party-based Mobilization and Internet: The increase in the number of daily internet and mobile app users has correspondingly changed the nature of outreach and brand management across a range of fields, including politics[2]. For political parties, this has signaled a need to evolve culturally, both as organizations, and in terms of how they approach their communications. Chadwick notes that "political parties are undergoing a process of adaptation to post-material political culture brought on by the affordances and uses of digital media[3]." These developments have helped create new means for parties to build and rejuvenate themselves (or indeed lose momentum with constituents, compared to their rivals), powered by "new digital foot soldiers" creating new frontlines of their outreach strategies[4]. 
Unconventional techniques, made possible by information and communication technologies, have become a widely popular means of distributing news, discussing political issues [5], thereby building political narratives leading up to an election. In their study of various phases of election campaigns, Andrea and Drik [6] classify them into four categories: pre-modern, modern, professionalized and mediatized phase. The final phase of mediatization, according to them, is distinguishable by key traits such as new applications of communication technologies and quantitative data in election campaigns[6]. This phase, marked by changes in the political institutions due to the increasing significance of media, especially online media sets the stage for our work on technology adoption among grassroot political workers.

In the current mediatized environment, the internal and external stakeholders of political parties establish new "participative and communicative structures" to foster new forms of engagement[5]. In addition to opening new platforms for fulfilling modern demands that emerge in digital political engagement, the online outreach allows for cost-effective means of certain forms of collective action [7], and help create new ways of both widening the reach of who can actively engage in a campaign, rather than be passive supporters, partly by offering more emotional access[6], and a public-like forum, which can circumvent the established structures of political authority as well as the symbolic dominance of mainstream media[8]. Increasingly, in order to sustain, political parties need to equip themselves with technically-skilled personnel, who may not contribute the traditional resources valued to campaigns such as time, money, civil skills, or muscle, but bring value through their knowledge of the latest technologies that can be used for a range of political purposes [9, 10]. In addition to that, social media use not just impacts shaping of political communication but shaping the media itself in order to serve well as mediator among citizens and between citizens and government[11].

Mobilizing the digital foot soldiers within the party machinery and party supporters on the outside becomes a crucial act towards mobilizing voters, a process that has increasingly taken on digital proportions in the last decade. Mobilization, here, is defined as the development of a social relationship between two types of actors, the individuals and the parties. Mobilization broadly includes three processes: interest formation (cognitive dimension), community building (affective dimension), and employing means of action (instrumental dimension)[12]. In her work, Norris explains how ICTs can strengthen direct pluralist democracy by facilitating the mobilization of multiple interests to influence the political process [13]. On the one hand, it is widely proposed that online outreach methods substantially benefits resource deficit organizations that do not traditionally have access to mass media outlets [11], and on the other hand, scholars advocate that the Internet may change the, "logic of participation" through mobilization by creating new platforms for participants who would have otherwise remained out of political space[14, 15]. Further, internet supports "mesomobilization" by providing a medium and new tool for groups and organizations to coordinate and integrate other groups, organizations and networks for expressing their solidarity towards a cause[16]. The Cambridge Analytica controversy and the exposing of the role of social media in hyper local targeting, generated a discourse around political social media communication and the top down fashion of manufacturing people's political opinions [17]. However, scant attention was paid to understand how grassroots campaigns and the actors involved are impacted by these changes in political campaigning. Our work is an important step forward in examining this aspect of the transition in the electoral landscape in India, by looking at Madurai and Thiruvananthapuram.

Digital Political Mobilization in India: India has recently witnessed various initiatives spearheaded by the election commission, political parties and social movement groups that use information and communication technologies (ICTs) to promote electoral reform and political mobilization [18]. Our work highlights the groundlevel use and implication of these technologies illustrated through experiences of boothworkers. Even with the rapid indian onboard onto social media platforms, as compared to the mainstream media, the number of active voters on these platforms are comparatively fewer - Twitter's monthly active users are at 30-33 million, Facebook's are at 270 million, and WhatsApp at more than 230 million. However, ICTs and the ease with which the middle and upper classes can access and use them plays a central role in enabling the targeting and re-engagement of mostly these classes with the political process [19]. Since journalists' use the political discussions and updates made by politicians on social media as their official source of information, the information, as well as the misinformation generated in social media platforms also reaches the non-social media users through print and e-news, and shapes the political opinion of majority population [20]. The conversations that are happening in the digital space still stays relevant in the country which is marked by huge digital divide.

The 2014 election, touted as the first social 
media election in India, had a total of 56 million election-related tweets posted within the span of 2 years and 4 months before the elections [21]. Bharatiya Janata Party, a major rightwing political party, with the first mover advantage, adopted the three key elements of political communication - political organisations, the audience and the mediathrough which political actions are "conceived and realised" in their election campaign strategy [22]. In addition to their political network, at an organisational level, BJP has the support of its cultural wing - Rashtriya Swayamsevak Sangh (RSS), a disciplined and well connected network of grassroot workers engaged in social mobilization. RSS functions as bedrock not only for organising key campaign activities, but also provides feedback for improving the campaign strategies of BJP [23].

Some of the prior works in this area have tried to understand the politics of abusive exchange on social media[24], how right-wing political volunteers of right-wing political party use social media online archiving [25], the role of media which includes print, television and social media in the making of the "common man" [8], how parody and satire on the web are intervening within political and social discourse within national public spheres [26], how internet hindus function in the Indian cyberspace[27], the representation of Indian women's political views on the twitter verse [28], and the social media usage by specific Indian political parties [29, 30]. With our paper, we attempt to understand the way grassroots political workers use social media and the difference the internet has brought to their everyday life and work.

Social Movement Repertoire: In their work, Jeroen Van Laer \& Peter Van Aelst[1] present a typology for a new repertoire of social movement action that "illustrates how the internet has shaped and is shaping social movements and the tactics they use to pursue their claims." The typology examines two dimensions - firstly, it looks at 'real' or traditional actions that have been employed in social movements and how they are supported and modified by the internet today. Apart from these, there are strategies that have emerged because of the internet which are 'virtual' actions and are hence, relatively new additions to the repertoire of social movement action. These internet-supported and internet-based actions have 'complemented and expanded' available collective actions, congregating to form the 'digitized' repertoire of social movement action. The second dimension evaluates the low or high threshold of the action in terms of practical participation cost involved, such as resources needed (energy, time and money) as well as the potential cost or risk of undertaking the action, for example, getting arrested for an illegal activity.

The permeable nature of the tactics is reflected in the typology - for example, an email petition which is a variant of a traditional form of protest that has found efficiency on an electronic platform, would be in the internet based category but placed closer to the internet supported space along the continuum. Similarly, signing an email petition might hold negligible costs in comparison to using hacktivism as a strategy, which is a higher threshold activity considering the skills required and the legality of the act itself. The typology takes into account the literature surrounding how the internet supports and creates new modes of collective action with regard to organization, mobilization as well as the transnational character that social movements have been adopting with the changing impact of global capital on national policies and people. This framework stresses on the principal potential of the internet to minimize mobilizational costs of politico-social action as it is an environment that redefines space and time constraints.

\section{Methodology}

Two authors of the paper engaged in an ethnographic study of the urban, grassroots electoral process in Madurai, Tamilnadu and Thiruvananthapuram, Kerala. This involved interviews, attendance at party meetings, and observations at poll events such as in door-to-door campaigns and public gatherings. We observed both locations from November 2019 to the respective dates of polling in the two locations in May 2019. Interviewed persons include party leaders (11), party IT cell members (9), political strategists working on campaign logistics as well as social media and marketing (7), party activists such as post holders or booth committee members (31), journalists (3), and citizen influencers (5) who do not have formal positions in the party, but were engaged in political activity. We recruited interviewees from across the political spectrum and and ensured that we followed the campaigns of and met with representatives of all the major national and state parties that had a candidate in the fray directly or in coalition.

Shadowing the booth workers, who included party supporters and volunteers to political committee office bearers or elected representatives such as ward councillors, we observed the activities that occurred at various phases. These workers were typically referred to as 'squad groups' which could be either male, female, or mixed. Our observations included the planned activities such as voter verification visits or canvassing at voter's home or group activities such as road shows or small home-based gatherings and ad-hoc activities such as interactions at street junctions, 
or unplanned community visits. We also observed party committee planning and strategy meetings, and were able to interview party functionaries on their management of the process - such as media material creation, booth worker surveillance, management of influencers such as party patrons, teachers, residence association chairpersons etc. The interactions we had with respondents (and each other) influenced the framing of the interview schedule. The interviews were recorded and then transcribed verbatim, translated when required and analyzed through a grounded theory approach. The two primary researchers read each others' interviews, and coded them, and the coding schema was polished over several hours of iterative whiteboarding. The high-level thematic areas that surfaced in the initial interviews were further used to align the interview questions in the later part of the fieldwork. Mobilization emerged as a central thematic area.

The two locations we picked were partly due to our own expertise with elections - both researchers are local to the respective regions. Unlike in the rest of the country, where the BJP enjoys a very significant lead over its rivals, in the south, where the states of Tamil Nadu and Kerala are located, it has a relatively minor presence. Tamil Nadu is important in the 2019 election because of the changes in its political scenario - the top political parties in the state, the Dradvida Munnetra Kazhagam (DMK) and the All India Anna Dravida Munnetra Kazhagam (AIADMK), lost their charismatic leaders, who drove their respective vote banks. We selected Madurai, an urban constituency in the state that expected a three way race between the ruling AIADMK alliance with the BJP, which is in power at the center in New Delhi, the DMK alliance with the Communist Party of India-Maxist (CPIM) and INC, and a possible third front with splinter groups of the AIADMK and newly formed parties. In Kerala, we selected Thiruvananthapuram, which was widely expected to have a well-matched three way contest between the ruling INC, the CPIM, and the BJP. In both locations, we sampled respondents through a mix of connections through party offices and journalists, and snowballed interviewees through these initial connections.

Using the typology presented in the "digitalized social movement repertoire", we enlisted the tools the booth worker used at the various phases leading up to the election and created memos describing the activity, the internet use and the layered commitment required of the worker to undertake the tactic. These details were circulated among our research team, who work on qualitative and quantitative social media studies and it guided the evaluation of the tools in terms of the dimensions presented in the typology - internet based/supported or high/low threshold of cost and risk. The authors used this discussion, to validate the placement of the tools within the four quadrants in the typology.

\section{Findings}

We categorize the mobilizational tools used by political actors according to the typology and portray it through the diagram in figure 1 . We elaborate on the items distributed across the four quadrants (Q1 - Q4) through an analysis of our observations and interactions.

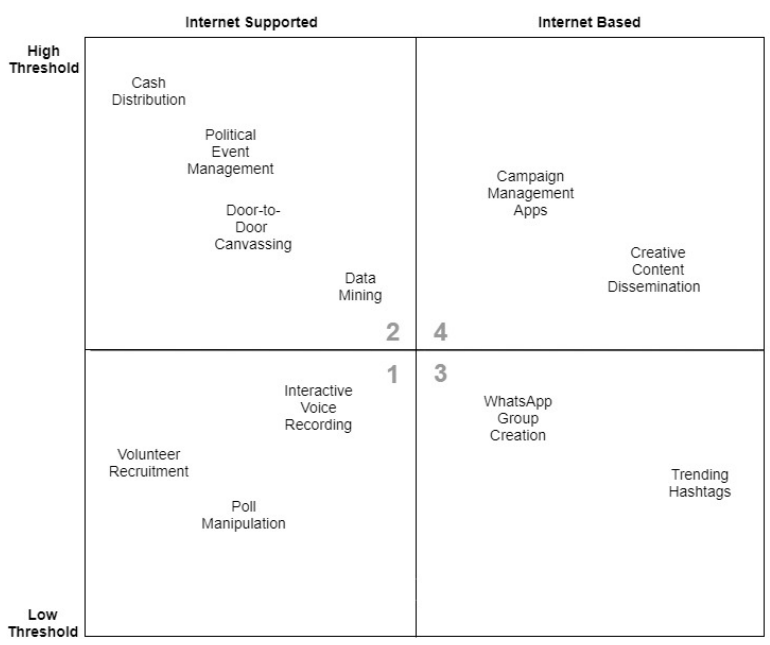

Figure 1. Typology of Digitalized Political Mobilization Repertoire

\subsection{Q1 : Low-threshold Internet-supported}

Interactive Voice Recording: Social media allows the leader of a party new means of supporting booth work through direct action. The chief minister of the state, J Jayalalitha, was an iconic politician who ran a personality-centric campaign for her party highlighting her photographs and moniker, Amma, literally meaning 'Mother', on campaign material, often more significantly than imagery or discourse of either the party or the local candidate [31]. One of the unique technology-supported experiments attempted in the 2014 campaign was Interactive Voice Response conversations with voters, which after an initial phone engagement would move to a recorded message from Jayalalitha.

"In 2016 elections, through IVR a customised call was made to the individual voter of every constituency. Voice of Amma, greeted the individual, promised the voter that she will address the issue 
that prevailed in their constituency and requested the voter to vote for her party. Few people believed that Amma herself spoke to them - Manohar, Booth Worker, Madurai"

Technology allowed the spectre of direct contact between the leader and the population, allowing booth workers to refer citizens to a means of listening to a message that appeared to be crafted to them individually. The IVR thus acts as an enhanced pamphlet. The technological artifact here cannot be extracted from the context and history of personality politics in Tamil Nadu, where the long dead former chief minister M G Ramachandran, and erstwhile leader of Jayalalitha's political party, the AIADMK, is still symbolically critical in bringing votes for his party. Indeed, several years after his death, a significant base of voters still believed he was alive and well. The viscerality of voice outreach in this environment is highlighted in the belief, by some potential voters, that the IVR was a direct conversation between them and Jayalalitha.

Poll Manipulation: This relatively low threshold activity involved gaming television polls by getting a number of volunteers or paid election workers to repeatedly vote to manipulate the outcomes of a media event. Mobilization has two forms here - first, the aggressive mobilization of people in networks to act on a specific event. Where a small number of volunteers can vote repeatedly, they may do so from the confines of a single office. But in other cases, the mobilization may involve getting a disperse set of supporters to get online in a very short period of time and vote aggressively.

"There are Teams in the head office whose function is just to watch all the TV channels and inform us in advance about the (audience) polls on TV Channels. At the end of every debate, through online polls, (such polls) ask the stance of public on a particular social or political issue or the leader whom they support etc. (At this point) all the IT wing members, as a team respond to these polls with the stand which our party proposes"-Ahmad, IT Wing Secretary, Madurai

Often, such votes need to be made using SMS, which involves a cost for the volunteer. Such mobilization for political parties is inspired by vote manipulations for television talent shows in which performers on television may be ranked based on the number of votes they receive.

\subsection{Q2: High-threshold Internet-supported}

Door-to-Door Canvassing: Being an effective canvasser is a central criterion on which a booth worker is selected to work for a candidate. In addition to soliciting people in their homes, booth workers organize and lead group discussions, in which they relay the key positions of a candidate as well as use group persuasion as a means of mobilizing the voters.

These activities present logistical challenges - a booth worker must be able to conduct the door-to-door work at times when they are likely to encounter their intended audience. They must also ensure that if a group activity needs to be conducted, then they will be welcomed within the physical spaces of a potential voter's home, or if they do this in their own physical spaces, that the requisite audience shows up for a session. In the past, the typical outreach process revolved around working hours, which meant that male voters were more likely to be solicited in weekends and evenings, while females in a household would be approached during afternoons. In location 1, we found that the growth of workforce participation of females impacted the logistics of how solicitation could be done.

"these days women are also going to work. So we cant go to their home anytime and every time for campaigning. Also, it is easy for candidates to reach slums and economically weaker section of the society very easily. But people in gated societies and in posh localities of the city don't encourage campaigners. So pamphlets and posters were used in the past to let the people know about the candidate. Today, this is replaced by WhatsApp messages, Facebook posts and YouTube videos"- Mannan, Booth Worker, Madurai

The quote above shows how class issues impact the ability of a booth worker to approach their client populations. First, the hours of work a booth worker keeps can influence who they have access to. Second, gender dynamics impact who can be approached and when - there may be a preference for female only outreach for households that were likely to have only female members at the time of the visit, and likewise, the comfort and effectiveness of a single female booth worker operating in male spaces may need consideration.

Changes in urbanization patterns have meant that wealthier voters are harder to reach through door-to-door solicitation. Pamphlets can only be placed where a household's door or main entrance is accessible, likewise, street level posters have limited 
value in attracting voters who are not part of daily foot traffic. Social media outreach could be useful both for organizing door-to-door visits more effectively as well and for outreach to those stakeholders that were otherwise difficult to reach in gated communities or apartment complexes.

Cash Distribution: In Tamil Nadu, cash and freebies have historically been known to be part of the campaign outreach process. In the most recent election, prior to our research, the word on the street was that cash was distributed in packets snuck into the morning newspapers - the move was so successful that polling hit a record $89 \%$, and the technique of cash distribution got its own name - the "Thirumangalam formula". In this environment, booth workers must be trustworthy and competent, because millions worth of unaccounted cash is distributed to potential voters, with no confirmed means of knowing if the giveaway will bear fruit. Political parties typically appoint people of means to be as district level post holders, because in taking on this position, the individual often commits to spending their own funds to ensure a victory for the party. Being a significant post holder can be a means of various forms of earning down the line through being a middleman in transactions, but doing so requires showing some intent to the party as well.

Booth workers who work for a political party during the election are paid a wage of Rs. 300 per day in addition to food, snacks and transport service. While this remuneration plays a part in attracting workers, being a party member is also a means of signaling importance in society and a segue into networks that can get things done. The booth worker bears the risk of the entire amount of unaccounted cash that they are assigned, and must often think of creative ways of distributing to the right people who are likely to vote for the party, or at least definitely not vote for the party if they don't get a token amount.

Booth workers have traditionally worked out ways of hiding their transactions during election season, the circulation of cash distribution info on social media and on monitoring apps added a new layer of complexity to their work. The Election Commission of India (ECI) built a mobile application called $c$ VIGIL enable citizens to report violation of election code of conduct, while this app was used by the booth workers to report issues related to the other parties, they needed to be cautious that if they themselves indulged in illegal work, the right person with the tool could easily report them. ECI, launched another app named Voter Helpline to develop a culture of responsible electoral engagement. This app turned out to have an unintended consequence to allowing parties better granular knowledge on their likely voters at the booth level. Booth workers of Location 1 used this app for accessing the details of the voters. They see this app as an updated, easy to access, handy and paper saving version of voter slips, which has basic information about the voter.

\section{"Voter Helpline has updated information about all the voters. Our boys learned how to use this app immediately. With the available updated information, we identified the list of neutral voters and distributed cash and freebies to them"- Ramanan,Booth Worker, Madurai}

Essentially, the booth workers were able to extrapolate, at the family level, from the existing data who were their likely voters at most booths. Consequently, by the time a booth worker is at a doorstep, they have a fairly good idea of whether they are talking to a swing vote household, and whether a cash donation is likely to bear fruit. The booth workers can keep track of whether the individuals they thought were likely voters for their party did or did not show up at their polling stations on the day of the election. By a certain hour in the day each person who was recorded as having received a donation or noted as a likely voter will be visited physically or called over the phone and pressurizes them to vote. This same information can also be aggregated at the booth levels and sent up the chain to give campaign managers a better sense of where they stand with the polling.

Political Event Management: Politicians generally organise events such as guest lectures, rallies, roadshows, etc to meet the people directly and discuss their agenda. Presence of huge crowd at these political events is one of the means to display the strength of the parties both to the people and the rival parties. With the support of technology, they are not only able to mobilize people for the events, but they are also able to come up with new ideas for organising the events which are different from the conventional ones. We found that booth workers used Google ads, which allows customization based on target location to invite people in a specific geographical location to participate in the events, and to create variations for one single ad.

Getting good turnout at a political event from their assigned localities is one of the key functions of a good booth worker. With the onset of social media as one means of announcing events, a question booth workers need to grapple with is how many of those who respond to an event will actually show up. In this case, boothworkers may live cast an event, but still rely on their analog means to round up attendees. Here, relying on innovations to encourage in-person attendees 
can be handy - one party used a SelfieWith(candidate) technique to add value to physical attendance [32]. This both helped to make sure that people got a chance to publicly perform their allegiance to a candidate by posting their selfies, but also brand the candidate online as an approachable person, willing to spend time interacting with citizens on an individual basis.

Data Collection and Analysis: For large populations who have skipped the desktop and laptop stage to the smartphone era, mobile apps are an increasingly popular tool for the party to collect voter data directly from the electorate through booth workers without 'skilling' them. At the booth office, we noticed that workers continue to rely on notebooks, diaries, political reports and forms that have won them elections in the past. Demographic data in terms of age, religion, caste, occupation, party affiliation collected in pieces through booths using apps and consolidated at a state level digital platform, presents a map of action for the new crop of digital content generators, strategists and marketers who have become crucial stakeholders in the 'new digitized elections'.

"When we go to each house, we know the info, but we still ask and enter this info - Is this person a supporter of our party, or supporting rival party? If our party, is this person here? If not, can we bring this person to vote? Collect Mobile number. The app has GPS. We don't need an internet connection for entering this info. The info gets uploaded when we are in an area that has an internet connection. Once this is done, we know the areas that we are strong in and where we are weak. It's the same squad work that we used to do. We have just made it digital. "- Prakash, Party Area Committee Member, Thiruvananthapuram

In addition to direct collection of demographic data, party members noted purchasing data from local vendors who collect customer information, such as their Aadhar (national ID) number from shops such as jewellery or mobile shops where this information needs to be deposited for a purchase. This information is then used to nudge likely supporters, but also to potentially suppress those who are likely to vote against a party.

\subsection{Q3: Low-threshold Internet-based}

WhatsApp Group Creation: While there have been steps taken by social media companies to regulate what politicians do on their platforms, parties and the booth workers operating on their behalf continue to use the affordances of the technology for a range of outreach activities. In location 2, we found that the going rate for WhatsApp groups that could be purchased from vendors was Rs. 400 (approximately \$6 USD) per 250-member group. Such groups were put together by people who had access to lists of phone numbers, such as employees of telecom companies, who would ping a number to check if it ran WhatsApp, following which the phone numbers would be involuntarily added to a group.

On the ground, there is also a cottage industry of companies that provide outreach across party lines. For instance, one vendor charged Rs.100,000 per assembly constituency for sending an individual WhatsApp message with approximately 500 characters. These companies at the most basic level were able to give access to phone numbers, but given their access to individuals with technical skills, some had evolved into providing value-added services for campaigns. One vendor provided a "21 days messaging strategy" in which on first 7 days, negative messages are sent to tarnish the image of the rival party, followed by a week of messaging about welfare schemes and the election manifesto of the party, followed by a last phase in which the candidate is the main key for the next 7 days and on the third phase, they promote their candidate.

"In WhatsApp, a group named "Tamilian"
was created. People joined the group
as interesting information about Tamil
language and culture was shared on this
group. But on infrequent intervals, posts
were made in support of Seeman (a Tamil
ultra-nationalist politician). Similarly,
groups to promote spiritual messages are
created, on infrequent intervals, they posts
messages to support BJP"-Mahesh, Booth
worker, Madurai

Once a group is created, a normative argument is typically offered in addition to the political imperative. We found that while some campaigns used WhatsApp groups named for the candidate, others aimed to appeal through alternate constructions that appealed ideologically or to some form of identity creation that held a deeper affective appeal. A case in point is the pseudo-group we see in the quote above. Social media platforms, especially Whatsapp groups, become arenas for brand building and networking for booth workers. At each node of party hierarchy - state, district, constituency and local area, exists an official WhatsApp group of elected representatives, party leaders and other important party office bearers connected to the party IT wing. Clusters of unofficial WhatsApp groups initiated by local party workers also mushroom along these nodes, which might involve the candidate, a few important local stakeholders such as local party 
leaders, government officials, journalists and residents' association office bearers who have a sway over groups of people within the locality. These are formed under various collective identities such as residential membership which may intersect with religion and caste based identities. And then there are groups formed based on caste and religion, often male only, without the masquerade of a less divisive agenda. These groups may or may not have rival party members, by design, according to the intent of the group. We were told, heterogeneous party affiliation in group membership was one way of gaining information regarding the opposition's arguments in an otherwise echo chamber environment.

Trending Hashtags: A reality of political events on the ground is that they require a significant amount of behind the scenes management in planning an event - such as the location, media outreach, crowd management, and the handling of the key figures the politicians themselves. These can be even more tricky for a political party in opposition, since the state may choose to use its power to manipulate an opposition party's access to public spaces, its right to congregate, access to state media etc. In conversation with political operatives, we found that social media reduced the need for some kinds of physical events involving stages, loudspeakers, and cadre organizations since parties had better means of doing outreach in those areas where an expensive physical meeting may not have the desired 'bang-for-the-buck' in terms of voter mobilization. In these locations, having strong social media based outreach reminds voters that they are on the minds of the party, offsetting some of the attention lost by not doing a large physical event.

While outreach for a physical event seems like an obvious thing that social media enables - thus replicating the affordances of flash mobs by spreading the word on a political event, there is also the occasional crisis that can be enacted on social media. In one case, a political operative told us of a public event which was denied permission by a police official on a flimsy ground, presumably acting on the instructions the party's rivals, who were the party in power in state. In his words, the party immediately went on overdrive on social media calling out the ruling party and making it against the party:

"(after he cancelled the event) we were able to trend our hashtag within an hour. Later, the police officer himself called us over phone and requested us to not make any further posts in social media and granted permission for organising the meeting."Uma, IT Wing Secretary, Madurai
Party functionaries were able to quickly mobilize and turn the situation in favour of them. The creation of a villain - ruling party against democracy - found affective appeal online, and supporters of the party quickly piled on, which in turn brought the mainstream media into the fray. This case highlights how a social media affordance for trolling or doxxing a public official made him politically vulnerable and back off from action against a party. The specific case highlighted, of police or magistrate officials being used to gently block opposition parties is common in elections, and parties typically are restricted to expensive analogy processes of protest, such as taking out a rally outside a police station or collectorate, which would also probably take long enough that the window of opportunity for a political event would be lost. Social media allowed a relatively low-cost means of putting pressure on an official.

\subsection{Q4: High-threshold Internet-based}

Creative Content Creation: Booth workers consider memes as an essential non-violent political weapon. They either engage themselves or recruit specialists for designing memes to promote themselves and pull down the rival party. In addition to sound political knowledge, memes creators require basic technical skills to articulate themselves creatively. Some of the booth workers who were involved in physical fights in the past to establish their position of power, are now directing their energy towards countering the memes of the rival party.

"Generally, people check their social media accounts during their free time, mostly at night when they come back from work or after completing their daily routine. They prefer watching light-hearted or entertaining stuff such as memes, in that short time, instead of the conventional heated debates or long editorial pieces"Rasul, IT Wing Member, Madurai

Social media allows less established parties to bypass traditional gatekeepers, build narratives that reach a large audience which can simultaneously be picked up by on ground support. Political bipolarity in Kerala led by the Congress Party and the Communist Party of India (Marxist) have cultivated a political hegemony that coalesces in the centrist and centre left political spectrum through owned media of popular newspaper and TV channels. A far right party like Bharatiya Janata Party (BJP) attempted to underplay its 'Hindu-ness' to be palatable to the voters of the state, until the Sabarimala issue (the Supreme Court 
of India overturned a ban on the entry of women of menstruating age into Sabarimala temple in Kerala ) dropped right into the Overton window for the party. By emerging as the voice of the devotee (mainly upper caste and the sizeable and politically influential Nair community), it began grabbing mainstream media coverage as the leaders of the mainstream parties attempted to firefight the situation. Floating between mainstream and far right, the booth workers could pick and choose the narrative and customize according to the audience, staging a 'Hinduism in danger' atmosphere. Re-branding extremists pasts to cool conservatism and using provocative issues to gain agenda setting power are two winning strategies used by the BJP at the national level.

Campaign Management Apps: With the 'appification' of campaign management, new forms of surveilling and disciplining the booth worker emerge. The panoptic system of the app, although not strictly examined by party leaders, gives the impression that you are being tracked, your activity measured and hence, one has to fall in line. The gamification element, where the best performing workers with maximum number of house visits are publicly commended through a broadcast message on your phone, creates a model behavior of an ideal booth worker that they feel compelled to emulate.

“As part of the party's youth wing, we have to go to each house and talk about issues. There is a barcode (QR) on the poster that we carry to each house. We go to the house and scan this code on the app - Campaign Management. It is proof that we went to the houses. They can check this through satellite. If I dont do it, I might lose my position.”- Mujeeb, Party Block Secretary, Thiruvananthapuram

Conversations with party workers highlighted that booth work can tend to be shoddy - the booth workers may or may not work based on a cadre system, loyalties may be dependent on the political currency extended to them. In such a system, as the booth worker mentions, members of the surveilled are also active participants that hold up the system since there is a check on the other. In the normalization of this behaviour, you transform yourself into the subject surveilled. At this stage of introducing apps for campaign management, they are unsure whether these 'points' and 'levels' on apps could materialize into political patronage and future candidacy.

\section{Discussion and Conclusions}

The literature discussing digital developments in the political landscape, largely present arguments and findings centered around digital artifacts and their use by politicians. Our study shows that the tactical imperatives of campaign management have been changed by internet-based and -supported activities and that these have created significant demands on grassroots workers to effectively use and digital artifacts in their professional practice - both to continue doing things that no longer operate in the analog forms, but also to adapt to new forms of outreach and organization that complement traditional means of election work.

First, we see that the reducing cost of access to the internet, and the gradual importance of social media as a space for political discourse has made it central to both the organization of people, in which the grassroots workers play a central role and mobilization of content. Counter to the idea that social media is a democratized space for outreach, we find that internet-based activities are active spaces of contestation that resource-rich parties game through expensive targeted marketing, using the grassroots workers as the critical conduit for this information.

Second, we see that social media is changing the nature of the relationship between the party and its grassroots workers, creating automated systems of surveillance and discipline in the garb of efficiency. We also see how the internet- and big data-supported analysis works; how the unintended consequences of open data related to the electorate have created a new crop of professionalized campaigning that allowed parties to act on, at a very granular level, voter turnout, bribing, and mobilization.

Doing these effectively requires resources to access and manipulate the data, and act on it at the ground level. This puts cash-rich parties at a unique advantage in major elections. In this process, we see a rapid congregation of new stakeholders and different spheres of action such as political consultancies, digital marketers whose work often cannot be closely observed by monitoring agencies, leaving them to self-regulate in the high stakes environment of a general election. The outcomes of the Cambridge Analytica scandal have shown the risks of process manipulation through the widely used digital tools - our work shows how these functions on the ground. At present, the Election Commission of India is examining the spending of political parties on social media advertisements but our work shows the difficulty of effective monitoring on the ground when outreach cannot specifically be considered "paid advertisements." This work gives insight into the unique challenges of formulating a 
regulatory infrastructure that is more informed and evidence-based.

Future Work: Our work sets the foundation for a larger body of work on election campaigning in a digital technology era. We hope this leads to deeper ethnographic work on political workers themselves, the impact of gender on outreach work, as well as comparative work on the differences between regions and ideological formations in terms of how they impact grassroots outreach. Finally, we hope that this work contributes to a growing literature in $\mathrm{CSCW}$ and social media studies on ethics in election campaigns.

\section{References}

[1] J. Van Laer and P. Van Aelst, "Internet and social movement action repertoires: Opportunities and limitations," Information, Communication \& Society, vol. 13, no. 8, pp. 1146-1171, 2010.

[2] B. Bimber, "The internet and political mobilization: Research note on the 1996 election season," Social Science Computer Review, vol. 16, no. 4, pp. 391-401, 1998.

[3] A. Chadwick and J. Stromer-Galley, Digital media, power, and democracy in parties and election campaigns: Party decline or party renewal? SAGE Publications Sage CA: Los Angeles, CA, 2016.

[4] C. Vaccari and A. Valeriani, "Party campaigners or citizen campaigners? how social media deepen and broaden party-related engagement," The International Journal of Press/Politics, vol. 21, no. 3, pp. 294-312, 2016

[5] R. K. Gibson, P. G. Nixon, and S. J. Ward, Political parties and the Internet: net gain? Routledge, 2003.

[6] A. Römmele and D. von Schneidmesser, "Election campaigning enters a fourth phase: the mediatized campaign," Zeitschrift für Politikwissenschaft, vol. 26, no. 4, pp. 425-442, 2016

[7] M. S. Bonchek, "Grassroots in cyberspace: recruiting members on the internet or do computer networks facilitate collective action? a transaction cost approach," in 53rd Annual Meeting of the Midwest Political Science Association, Chicago, IL, vol. 6, 1995.

[8] S. Udupa, "Aam aadmi: Decoding the media logics," Economic \& Political Weekly, vol. 15, no. 7, pp. 13-15, 2014.

[9] S. J. Best and B. S. Krueger, "Analyzing the representativeness of internet political participation," Political Behavior, vol. 27, no. 2, pp. 183-216, 2005.

[10] M. Cantijoch, Reinforcement and mobilization: the influence of the Internet on different types of political participation. IGOP, 2009.

[11] W. L. Bennett and C. G. Activism, "Strengths and vulnerabilities of networked politics1," Information, Communication \& Society, vol. 6, no. 2, pp. 143-168, 2003.

[12] B. Nedelmann, "Individuals and partieschanges in processes of political mobilization," European Sociological Review, vol. 3, no. 3, pp. 181-202, 1987.
[13] P. Norris, "Draft chapter for the un world public sector report deepening democracy via e-governance," Harvard University, 2004.

[14] M. X. Delli Carpini, "Gen. com: Youth, civic engagement, and the new information environment," Political communication, vol. 17, no. 4, pp. 341-349, 2000.

[15] S. Ward, R. Gibson, and W. Lusoli, "Online participation and mobilisation in britain: Hype, hope and reality," Parliamentary affairs, vol. 56, no. 4, pp. 652-668, 2003

[16] J. Gerhards and D. Rucht, "Mesomobilization: Organizing and framing in two protest campaigns in west germany," American journal of sociology, vol. 98, no. 3, pp. 555-596, 1992.

[17] N. Persily, "The 2016 us election: Can democracy survive the internet?," Journal of democracy, vol. 28 no. 2, pp. 63-76, 2017.

[18] R. Gowda and H. Gupta, "Tracking and explaining e-participation in india," in International Conference on Electronic Participation, pp. 66-81, Springer, 2010.

[19] K. Keniston and D. Kumar, "The four digital divides," Online erişim, vol. 21, p. 2010, 2003.

[20] V. Sambandan, Computer-mediated communication and the ascent of Narendra Modi. The Centre for the Study of Journalism, Culture and Community, 2015.

[21] DNA India, "How social media played game changer for election 2014 in the world's largest democracy," 2011 (accessed June 18, 2019).

[22] B. McNair, An introduction to political communication. Routledge, 2017.

[23] B. Narayan, "Modis modus operandi in the 2014 elections," Economic and Political Weekly, vol. 49, no. 20, pp. 12-14, 2014.

[24] S. Udupa, "Gaali cultures: The politics of abusive exchange on social media," new media \& society, vol. 20 , no. 4, pp. 1506-1522, 2018.

[25] S. Udupa, "Archiving as history-making: Religious politics of social media in india," Communication, Culture \& Critique, vol. 9, no. 2, pp. 212-230, 2015.

[26] S. Kumar and K. Combe, "Political parody and satire as subversive speech in the global digital sphere," 2015.

[27] S. Mohan, "Locating the internet hindu political speech and performance in indian cyberspace," Television \& New Media, vol. 16, no. 4, pp. 339-345, 2015.

[28] S. Anderson, "India's gender digital divide: Women and politics on twitter," ORF Issue Brief. Observer Research Foundation, 2015.

[29] N. T. Kanungo, "Indias digital poll battle: Political parties and social media in the 16th lok sabha elections," Studies in Indian Politics, vol. 3, no. 2, pp. 212-228, 2015.

[30] T. A. Neyazi, A. Kumar, and H. A. Semetko, "Campaigns, digital media, and mobilization in india," The International Journal of Press/Politics, vol. 21, no. 3, pp. 398-416, 2016.

[31] U. Skoda and B. Lettmann, India and Its Visual Cultures: Community, Class and Gender in a Symbolic Landscape. SAGE Publishing India, 2017.

[32] A. Karadimitriou and A. Veneti, "Political selfies: Image events in the new media field," in The digital transformation of the public sphere, pp. 321-340, Springer, 2016. 